\title{
Prescribing patterns and cost analysis of anti glaucoma medications in a tertiary care teaching hospital
}

\author{
Elfride F. S. ${ }^{1}$, Kishore S.R. ${ }^{2}$, Philip $\mathrm{S}^{3}$ \\ ${ }^{1}$ Dr Elfride Farokh Sanjana, Professor, Department of Ophthalmology, Pondicherry Institute of Medical Sciences, \\ Kalapet, Pondicherry, India, ${ }^{2}$ Dr. Kishore Sastha Ram V., Lecturer, Department of Pharmacy College of Health Sciences, \\ Mizan Tepi University, SNNPR, Ethiopia, ${ }^{3}$ Dr. Serin Philip., Medical Claim Officer, Dar al Shifa hospital, Kuwait.
}

Address for correspondence: Dr Elfride Farokh Sanjana, Email: Elfridesanjana@gmail.com

\begin{abstract}
Aim: To study the prescribing patterns and cost analysis of anti glaucoma medications in a tertiary care teaching hospital. Materials and Methods: This was a prospective study conducted in 62 patients of either sex who presented in the Department of Ophthalmology with an established diagnosis of glaucoma as per Asia Pacific Glaucoma Guidelines (SEAGIG). A specially designed proforma was used to collect data. Visual acuity with and without correction, intraocular pressure measurement with applanation tonometer which was corrected with pachymetry, stereoscopic evaluation of optic nerve head and Humphrey visual analysis was done to establish the diagnosis of glaucoma. All prescriptions were analyzed for the nature of drugs prescribed, percentage of prescriptions that included mono therapy versus fixed dose combinations, the preferred regimen chosen and switch over amongst the various classes. Results: The incidence of glaucoma was maximum in the $5^{\text {th }}-6^{\text {th }}$ decades of life. Mean age was $58+l_{-} 13.781$, with males $63 \%$ and females $11.29 \%$. Both eyes were affected in $49(79.03 \%)$ of patients. Risk factors were identified commonly diabetes mellitus and hypertension. Thirty $(50 \%)$ of patients were on beta blockers, followed by prostaglandin analogues 13(21.6\%) and fixed dosed combinations comprising 12(20\%) and alpha agonists 5(8.33\%). The cost per bottle of monotherapy and fixed drug combinations was analyzed and beta blockers were the most economical drugs in the management of glaucoma. Conclusion: Beta blockers remained the first drug of choice followed by prostaglandin analogues. No patient had clinically significant ocular or systemic side effects from beta blockers and it continues to remain a suitable economical option in patients with socioeconomic constraints in contrast to the Western world literature that choses prostaglandin analogue over beta blockers.
\end{abstract}

Key words: Beta blockers, Cost analysis, Fixed dose combinations, Prostaglandin analogues

\section{Introduction}

Glaucoma refers to a spectrum of ophthalmic disorders characterized by slow progressive degeneration of retinal ganglion cells that leads to permanent deterioration of the visual filed and loss in vision. It manifests with functional and structural changes along with increased intraocular pressure which is amendable to medical treatment to minimize disease progression $[1,2,3,4]$. Glaucoma is classified as primary and secondary and further based on configuration of the angle as open or closed angle. Glaucoma is the third

Manuscript received: $04^{\text {th }}$ December 2016

Reviewed: $10^{\text {th }}$ December 2016

Author Corrected: $19^{\text {th }}$ December 2016

Accepted for Publication: 27 $7^{\text {th }}$ December 2016 leading cause of irreversible blindness with an estimated 66.8 million people with visual impairment and 6.7 million blind from glaucoma [5]. India has 11.2 million people over the age of 40 years with glaucoma, and with increased longevity this number is estimated to increase to 16 million by the year 2020 [6].

The Chennai Glaucoma Study, Vellore Eye Survey, Andhra Pradesh Eye Disease Study and The Aravind Comprehensive Eye Survey are all regional landmark population based studies that have well established the prevalence and demographic of Glaucoma in the southern parts of India $[6,7,8,9]$.A step ladder pattern to 
management of glaucoma is followed with primary intervention being medical management [2].

Management of glaucoma as per SEAGIG Guidelines [10] recommends establishing a diagnosis, followed by a baseline intraocular pressure measurement, setting target intraocular pressure and initiating therapy. With a wide number of anti glaucoma medications available to the ophthalmologist, prescribing patterns show considerable variation, with prostaglandin analogues and beta blockers being the preferred first line of drugs [10].

We aimed to determine prescribing patterns and side effects of various anti glaucoma drugs in our hospital.

\section{Materials and Methods}

This was a prospective study done over a period of six months after approval from institutional ethics committee. Sixty two patients of either sex with a well established diagnosis of glaucoma (as per SEAGIG Guidelines) were included in the study [10]. A specially designed proforma was used to collect data which included patient demographics, past medical and medication history, socioeconomic status, and systemic comorbidities. History of previous ocular surgery and present medications for each patient was documented. In patients with known and newly diagnosed glaucoma all prescriptions were analyzed for the names, dose, frequency, duration and class of drug prescribed, percentage of monotherapy versus fixed drug combination and cross over between classes was documented for those patients who did not achieve the target intraocular pressure. Only topical medications were analyzed although tablet acetazolamide was the only oral anti glaucoma medication prescribed. Systemic co morbidities which accounted for risk factors in primary glaucomas were documented.

\section{Results}

Demographic analysis showed mean age group of 58+/_ 13.781 years with patients in the range 50-59 (35.48\%) having the maximum incidence of glaucoma. Males constituted to $39(63 \%)$ and females 23 (37\%) of the patients studied. Amongst the patients included in the study 18(29\%) were patients with a known history of glaucoma and $44(71 \%)$ were newly diagnosed patients. Both eyes with asymmetrical involvement was seen in $49(79.03 \%)$ of eyes. Open angle glaucoma constituted to the majority of cases of glaucoma 39(62.90\%) followed by secondary glaucoma $15(24.20 \%)$, and primary angle closure glaucoma made up 7(11.29\%) of the total patients analyzed.

Diabetes mellitus was the most common systemic association $35(56.45 \%)$ of the patients studied, followed by Hypertension $27(43.55 \%)$. Target pressure was achieved in $43(69 \%)$ of patients who were managed medically, where as $2(3 \%)$ and $17(28 \%)$ of patients required laser and surgical treatment respectively.

Table-1: Distribution of anti glaucoma drugs

\begin{tabular}{|l|l|l|}
\hline Drugs & Patients (60) & Percentage (\%) \\
\hline Beta blockers & 30 & 50 \\
\hline Prostaglandin analogues & 13 & 21.6 \\
\hline Alpha 2 agonists & 5 & 8.33 \\
\hline Fixed dose combinations & 12 & 20 \\
\hline
\end{tabular}

Table-2: Dosing frequency

\begin{tabular}{|l|l|l|}
\hline Frequency & Patients (60) & Percentage (\%) \\
\hline Once daily & 13 & 22 \\
\hline Twice daily & 47 & 78 \\
\hline
\end{tabular}


Table-3: Types of drug regimen

\begin{tabular}{|l|l|l|}
\hline Type & Patients(60) & Percentage (\%) \\
\hline Single drug regimen & 47 & 78.33 \\
\hline Fixed dose regimen & 12 & 20 \\
\hline Triple drug regimen & 1 & 1.67 \\
\hline
\end{tabular}

Table 4: Ocular side effects of beta blockers

\begin{tabular}{|l|l|}
\hline Ocular side effects & Number of patients \\
\hline Hyperemia & 5 \\
\hline Burning & 4 \\
\hline Stinging & 2 \\
\hline Dryness & 3 \\
\hline Punctate keratitis & 2 \\
\hline
\end{tabular}

Table-5: Cost analysis of anti glaucoma medications per eye/both eyes

\begin{tabular}{|l|l|l|}
\hline Anti glaucoma medication & Single eye & Both eyes \\
\hline Timolol 0.5\% eye drops & Rs 284 & Rs 565 \\
\hline Betoxolol 0.5\% eye drops & Rs 288 & Rs 580 \\
\hline Latanoprost 0.005\% eye drops & Rs 2263 & Rs 4467 \\
\hline Bimatoprost 0.3\% eye drops & Rs 2628 & Rs 5212 \\
\hline Brimonidine 0.2\% eye drops & Rs 1423 & Rs 2847 \\
\hline Dorzolamide+timolol eye drops & Rs 1887 & Rs 3766 \\
\hline Bimatoprost +timolol eye drops & Rs 2233 & Rs 5621 \\
\hline Latanoprost +timolol eye drops & Rs 2233 & Rs 5621 \\
\hline Brimonidine+timolol eye drops & Rs 1660 & Rs 3321 \\
\hline
\end{tabular}

Beta blockers were the most commonly prescribed drugs in 30(50\%) of the patients, followed by prostaglandin analogues in $13(21.6 \%)$, alpha agonists in 5(8.33\%) and fixed drug combination in $12(20 \%)$ of patients. (Table.1) Dosing schedule is depicted in Tab 2. Timolol (0.5\%) was prescribed in $21(35 \%)$ and betaxolol in $9(15 \%)$ of patients. Latanoprost $(0.005 \%)$ was prescribed in $2(3.33 \%)$ in comparison to bimatoprost $(0.01 \%)$ in $11(18.33 \%)$ of patients Dorzolamide and timolol was the most commonly prescribed fixed dose combination $6(10 \%)$ followed by prostaglandin analogue and timolol and alpha agonist and timolol in $2(3.33 \%)$ each. Single drug regimen was effective in $47(78.33 \%)$ of patients. (Table. 3) Hyperemia was the most common side effect in patients on beta blockers (Table 4) and hypertrichosis in 7 patients on prostaglandin analogues. Hyperemia and bitter taste was most commonly encountered side effect in patients 
on alpha agonist and dorzolamide respectively. 13 (20.96\%) patients were lost to follow up. Cost to the patient per day was calculated by dividing the maximum retail price by the number of drops in each bottle and multiplying this with average number of drops prescribed daily. Costs of anti glaucoma drugs for single and both eyes are depicted in Table 5 .

Adequate counseling regarding the nature of the disease, drugs, dosing frequency, storage conditions and nasolacrimal duct occlusion was explained to every patient in an attempt to reduce systemic absorption and improve patient compliance and adherence. The cost of anti glaucoma medication per drop, per bottle, per eye and in both eyes per year were calculated in this study.

\section{Discussion}

The socioeconomic burden of glaucoma is large as it is now the second most common cause of irreversible blindness in India only after cataract with a projected estimate of 16 million people blinded by this condition by the year 2020 [6]. Lowering the intraocular pressure is the only method of treating glaucoma at present and this can be achieved in most patients with primary open angle glaucoma.

The demographic pattern which included $63 \%$ of male and $37 \%$ female with maximum incidence in the $5^{\text {th }}-6^{\text {th }}$ decade was not in consistency with results from other population based studies such as the Chennai glaucoma study [6] which showed a female preponderance in the incidence of glaucoma. Forty nine patients $(79.03 \%)$ of patients had bilateral involvement at presentation.

In our study 39 (62.9\%) patients had Primary Open Angle Glaucoma out of which 27(43.55\%) were males and $12(19.35 \%)$ were females. The Aravind Comprehensive Eye Survey found a higher prevalence of POAG in males $(68.75 \%)$ than females $(31.25 \%)$ [9]. Among the causes of secondary glaucoma phacolytic and pseudoexfoliative glaucoma accounted for $5(8.06 \%)$ and $4(6.45 \%)$ of patients respectively. The Chennai Glaucoma Study reported an incidence of $3.8 \%$ psuedoexfoliation in the rural south Indian population [6].

Forty three $(69 \%)$ of the 62 patients were treated with medical therapy alone. Beta blockers were the most commonly prescribed medication in $30(50 \%)$ patients of which $21(35 \%)$ received timolol $(0.5 \%)$ eye drops. This is in agreement with studies by Yadav et all that reported $93.88 \%$ predominance of beta blocker prescriptions followed topical carbonic anhydrase inhibitors $(15 \%)$, prostaglandin analogues $(8.88 \%)$ and cholinergics $(3.33 \%)$ [11]. A similar trend of predominance of beta blocker prescription was also seen in studies by Sharma et al [12].
Prostaglandin analogues were the second most commonly prescribed accounting for 13(21.6\%) of prescriptions in our study. Yadav et all reported an $8.88 \%$ use of PGA in their study where as Sharma et al reported 1\% [11.12]. PGA have superior efficacy and safety profile in comparison to other anti glaucoma medications which was demonstrated in a study by Singh et all [13] and western literature conforms to the same fact.

Our study had 12 patients who were on fixed dose combinations, most commonly dorzolamide +timolol because of their ability to achieve a nocturnal and diurnal intraocular pressure lowering similar to the results of a study by $\mathrm{Pal}$ et al [14]. Fixed dose combinations have the advantage of better compliance, decreased toxicity and side effects and wash out from the eye and this has been consistently demonstrated in studies by Hwang et al [15] and Yadav et all [11]. FDC were prescribed in $26.66 \%$ of prescriptions by Yadav et al and in agreement with our study of dorzolamide + timolol combination being the preferred combination.

Beta blockers were found to be cost effective in comparison to other drugs with the lowest price for timolol eye drops followed by betoxolol. The annual cost for timolol and betoxolol was Rs 565.70 and Rs 580.35 respectively. Beta blockers were the preferred class in our study similar to studies by Yadav et al[11] and Singh et al[12] taking into consideration the socioeconomic status of the patients being treated in all these studies. PGAs' were the most expensive with Bimatoprost between Rs 2555 to Rs 5215 for generic and patent versions respectively. Fixed dose combinations were in between the cost of beta blockers and PGA. The trend is different in western literature where prostaglandin analogues are the first drugs of choice. [16,17]. This can be explained by the socio economic constraints in India .

\section{Conclusion}


Beta blockers and prostaglandin analogues are the predominant anti glaucoma medications but with an obvious difference in the prescribing trends across the globe. Beta blockers remain the first line of drug in the medical management of glaucoma and this can be explained and accounted for by the socioeconomic constraints and poor level of literacy in out part of the world in comparison to western literature.

Dr Elfride Farokh Sanjana: Previous affiliation: (when the study was done) Associate Professor, Department of Ophthalmology, Sri Ramachandra Medical College and Research Institute, Chennai -600116

Funding: Nil, Conflict of interest: None initiated, Permission from IRB: Yes

\section{References}

1. Joseph $\mathrm{T}$ Dipiro. Pharmacotherapy- A pathophysiologic approach $.7^{\text {th }}$ ed. New York. McGraw Hill, 2001.pg 1551-1558

2. Allingham R, Shields' text book of glaucoma, $5^{\text {th }}$ ed. Lippincot Williams and Willkins.

3. Parikh RS, Parikh SR, Navin S, Arun E, Thomas R. Practical approach to medical management of glaucoma.Indian J Ophhalmol.2008.MayJun;56(3):223-30.DOI:10.4103/0301-4738.40362

4. Barbara Wells. Pharmacology $7^{\text {th }}$ ed. Mac Graw Hill. New York. 2009

5. George R, Vijaya L. First world glaucoma day. March 6,2008:Tackling challenges in India .Indian J Ophthalmol.2008;56(2):97-8.DOI:10.4103/03014738.39111.

6. George R, Arvind H, Baskaran M, Ramesh S Ve, Vijaya L. The Chennai Glaucoma study. Indian J Ophthalmol.2010 May-Jun;58(3):24345.DOI:10.4103/0301- 4378.62655.

7. Jacob A, Thomas R, Koshi SP, Braganza A, Muliyil J. Prevalence of Primary glaucoma in an urban south Indian population. Indian J Ophthalmol.1998;46(2):816.

8. Dandona R, Dandona L. Review of findings of Andhra Pradesh eye disease study :policy implications for eye care study . Indian J Ophthalmol.2001Dec;49(4):215-34.

9. Nirmalan PK, Katz J, Robin A.L, Krishnadas R, Ramakrishnan R, Thulasiraj RD, Teilsch J. Utilisation of eye care services in rural south India: the Aravind Comprehensive Eye Survey. $\mathrm{Br} \mathrm{J}$ Ophthalmol 2004.Oct;88(10):1237-

41.DOI:10.1136/bjo2004.042606.

10. South East Asia Glaucoma Interest Group. http//www.seagig.org.

11. Yadav AK,Patel V.Drug use in Primary open angle glaucoma.: A prospective study at a tertiary care teaching hospital.Indian J Pharmacol.2013.Mar;45(2):117-20. DOI:10.4103/02537613.108279

12. Sharma R,Khajuria R, Sharma $P$, Sadhotra $P$, Kapoor B, Kohli K ET AL/ Glaucoma therapy: Prescribing pattern and cost analysis. JK Science 2004 Apr-Jun;Vol.6(2):88-92.

13. Singh K, Shrivastava A. Medical management of glaucoma: Principles and practice. Indian J Ophthalmol.2011Jan;59(1):S88-92. DOI: 10.4103/0301-4738.73691.

14. Magacho L, Reis R, Shetty RK, Santos L.C, Avila MP. Efficay of Latanoprost or Fixed -Combination Latanoprost -Timolol in patients switched from a combination of Timolol and a nonprostaglandin medication. Ophthalmology 2006.Mar;113(3):442-45. DOI:http://dx.doi.org/10.1016/j.ophtha.2005.11.011

15. Varma R, Hwang L J, Grunden J W, Bean GW. Using diurnal intraocular pressure fluctuation to assess the efficacy of fixed-combination latanoprost/timolol versus latanoprost or timolol monotherapy. $\mathrm{Br} \quad \mathrm{J}$ Opthalmol.2010 Jan;94(1):80-84. DOI: 10.1136/bjo.2009.162107.

16. Carroll SC, Gaskin BJ, Goldberg I, Danesh-Meyer HV. Glaucoma prescribing trends in Austrailia and new Zealand. Clin Exp Ophthalmol.2006 Apr;34(3):213-8. DOI:10.1111/j.1442-9071.2006.01196.x

17. Kashiwagi K. Changes in trend of newly prescribed anti glaucoma medications in recent nine years in a Japanese local community. Open Ophthalmol J.2010 Apr;4:7-11.DOI:10.2174/1874364101004010007. 


\section{How to cite this article?}

Elfride F. S., Kishore S.R., Philip S. Prescribing patterns and cost analysis of anti glaucoma medications in a tertiary care teaching hospital . Int J Med Res Rev 2016;4(12):2193-2198.doi:10.17511 /ijmrr. 2016.i12.19. 